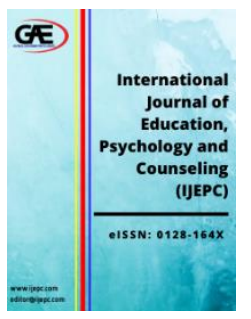

\author{
INTERNATIONAL JOURNAL OF \\ EDUCATION, PSYCHOLOGY \\ AND COUNSELLING \\ (IJEPC) \\ www.ijepc.com
}

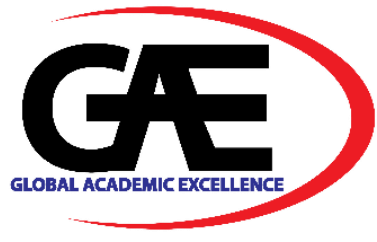

\title{
PEMBINAAN DAN PENGESAHAN SOAL SELIDIK FAKTOR KONTEKS PELAKSANAAN ELEMEN PENDIDIKAN STEM DALAM PENGAJARAN DAN PEMBELAJARAN GURU
}

\author{
CONSTRUCTION AND VALIDATION OF THE CONTEXT FACTOR \\ QUESTIONNAIRE FOR THE IMPLEMENTATION OF ELEMENTS OF STEM \\ EDUCATION IN TEACHER TEACHING AND LEARNING
}

\author{
Mohammad Azri Amatan ${ }^{1 *}$, Crispina Gregory K Han ${ }^{2}$, Vincent Pang ${ }^{3}$ \\ 1 SMK Likas Kinabalu, Sabah \\ Email: mazria_2387@yahoo.com.my \\ 2 Faculty of Psychology and Education, Universiti Malaysia Sabah \\ Email: crispina@ums.edu.my \\ 3 Faculty of Psychology and Education, Universiti Malaysia Sabah \\ Email: pvincent@ums.edu.my \\ Corresponding Author
}

\begin{abstract}
Article Info:
Article history:

Received date: 04.05.2021

Revised date: 17.05.2021

Accepted date: 31.05 .2021

Published date: 25.06.2021

To cite this document:

Amatan, M. A., Han, C. G. K., \& Pang, V. (2021). Pembinaan dan Pengesahan Soal Selidik Faktor Konteks Pelaksanaan Elemen Pendidikan STEM dalam Pengajaran dan Pembelajaran Guru. International Journal of Education, Psychology and Counseling, 6 (40), 180-192.
\end{abstract}

DOI: $10.35631 /$ IJEPC.640015.

This work is licensed under CC BY 4.0

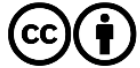

\begin{abstract}
Abstrak:
Ketiadaan instrumen kajian penilaian faktor konteks pelaksanaan elemen pendidikan STEM menyebabkan kajian ini dilaksanakan. Tujuan kajian ini adalah untuk membangunkan dan mengesahkan Soal Selidik Faktor Konteks Pelaksanaan Elemen Pendidikan STEM dalam pengajaran dan pembelajaran guru. Berdasarkan penerokaan literatur dan analisis soal selidik berkaitan yang sedia ada, konstruk dan item yang dikenalpasti menyumbang kepada konteks pelaksanaan elemen STEM dalam pengajaran dan pembelajaran guru telah berjaya dibangunkan. Kesahan muka dan kesahan kandungan instrumen melibatkan 13 orang pakar manakala, kesahan konstruk dan kebolehpercayaan instrumen disemak dengan menganalisis item-item soal selidik menggunakan perisian Statistical Package of Social Science (SPSS) Versi 25.0. Seramai 825 orang guru sekolah menengah dilibatkan dalam kajian ini. Muatan faktor untuk setiap item adalah dalam julat 0.538 hingga 0.819 , manakala nilai kebolehpercayaan (alpha) item adalah a=0.965. Keputusan kesahan dan kebolehpercayaan adalah tinggi. Ini menunjukkan instrumen sesuai ditadbir untuk kajian sebenar.
\end{abstract}

\section{Kata Kunci:}

Pembinaan Soal Selidik, Pengesahan Soal Selidik, Elemen Pendidikan STEM, Pengajaran dan Pembelajaran 


\begin{abstract}
:
The absence of a context factor evaluation study instrument for the implementation of STEM education elements led to this study being implemented. The purpose of this study was to develop and validate the Contextual Factors Questionnaire for the Implementation of STEM Education Elements in teacher teaching and learning. Based on the literature reviewed and analysis of the existing relevant questionnaires, the constructs and items identified contributing to the context of the implementation of STEM elements in teacher teaching and learning were successfully developed. The Context Factor Questionnaire went through face validation and content validity involving 13 experts, meanwhile, the construct validity and reliability of the instrument were checked by analyzing the questionnaire items using Statistical Package of Social Science (SPSS) Version 25.0. A total of 825 secondary school teachers were involved in this study. The factor loading for each item was in the range of 0.538 to 0.819 , while the reliability value (alpha) of each item was, $a=0.965$. The validity and reliability results indicate the instrument is suitable to be administered for the actual study
\end{abstract}

\title{
Keywords:
}

Construction of Questionnaire, Validation of Questionnaire, STEM Education Element, Teacher's Teaching and Learning

\section{Pengenalan}

Hakikatnya, perubahan dalam sistem pendidikan negara tidak dapat ditepis. Hal ini memerlukan suatu anjakan paragdima khususnya golongan pendidik (guru) yang merupakan jentera utama pelaksana dasar pendidikan negara. Joke dan Natalie (2012) menyebutkan sejajar dengan perkembangan dunia pendidikan abad ke-21, guru perlu memiliki kompetensi semaksimum mungkin agar dapat menjalankan fungsinya menyokong perkembangan pelajar. Kejayaan dalam mengurus perubahan dalam dunia pendidikan sudah pasti menjanjikan kesan positif terhadap kualiti pengajaran dan pembelajaran oleh guru (Mohamed, Afshari, Ghavifek, Siraj dan Abdul Razak, 2017). Walau bagaimanapun, suatu bentuk perubahan yang dihasratkan juga diakui mencabar untuk dilaksanakan, terutamanya dalam sesetengah keadaan ianya dikatakan mendatangkan gangguan terhadap zon keselesaan (Fullan, 2011). Oleh itu, sebagai tunjang utama pelaksana kurikulum, Mourshed, Chijioke dan Barber (2010) menyarankan agar aspek guru sebagai pelaksana kurikulum di sekolah harus diambil perhatian sewajarnya agar matlamat pelaksanaan suatu kurikulum benar-benar berjaya mencapai objektifnya. Dalam konteks pelaksanaan elemen pendidikan STEM di sekolah, sebuah instrumen bagi menilai konteks pelaksanaannya dalam pengajaran dan pembelajaran guru amat diperlukan. Matlamat usaha ini sebagai mengenalpasti sama ada suatu kurikulum yang dirancang pelaksanaannya benar-benar berada dalam landasan yang tepat ke arah mencapai objektif ditetapkan.

\section{Pernyataan Masalah}

Resolusi Kolokium Kebangsaan Pendidik STEM pada 2016 yang telah diadakan di Universiti Malaysia Terengganu (UMT) menjustifikasi permasalahan menyumbang kepada tahap pelaksanaan yang rendah terhadap pendidikan STEM dalam kalangan masyarakat di Malaysia, antaranya kurang penglibatan dan usahasama daripada pihak berkepentingan termasuklah institusi sekolah, pihak industri, NGO dan sokongan daripada media massa khususunya dalam mempromosikan potensi bidang kerjaya pendidikan STEM (Amimah, 2018). Tidak dinafikan wujud perkembangan positif melalui usaha kolaborasi pelbagai pihak seperti pihak sekolah dengan pihak industri, NGO dan media massa dalam aktiviti mempromosikan STEM (Meor, Copyright $\odot$ GLOBAL ACADEMIC EXCELLENCE (M) SDN BHD - All rights reserved 


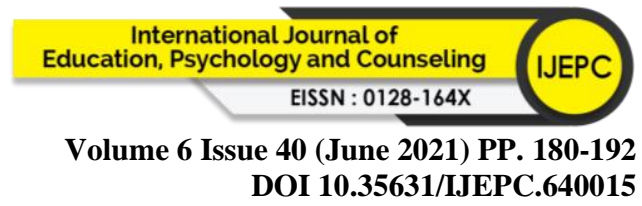

2017: Fazurawati, 2018; Ndubisi Ijeoma, 2018), namun perkembangan ini disifatkan masih tidak menyeluruh dan tidak mencukupi (KPM, 2018). Program-program yang diadakan dilihat cenderung bersifat terpilih melibatkan golongan tertentu sahaja serta masih kurang mendapat tempat dan liputan daripada pihak media massa (Amimah, 2018). Selain itu, pihak institusi pendidikan khususnya sekolah dilihat masih kurang peka dan kurang turun padang dalam penyampaian maklumat dan mempromosikan pendidikan STEM kepada masyarakat (KPM, 2018: Noraini Idris, 2018), namun ianya masih bersifat terhad dan lebih menumpukan kepada bentuk program seperti mengadakan pameran-pameran atau persidangan yang melibatkan bidang pendidikan STEM sahaja (Amimah, 2018). Maka, aspek konteks penyampaian maklumat berkenaan pendidikan STEM masih belum terlaksana sempurna. Oleh itu, sasaran untuk meningkatkan pelaksanaan pendidikan STEM itu sendiri secara menyeluruh masih belum dapat dicapai (Siew, Amir dan Chong, 2015; Amimah, 2018). Hal ini membenarkan situasi sebenar yang berlaku di sekolah, hakikatnya pihak pentadbir dan guru perlu memainkan peranan penting dalam memberi pendedahan kepada pelajar tentang bidang STEM yang sedang giat dipromosikan (Amimah, 2018; Noraini Idris, 2018). Namun, didapati input maklumat terkini yang ada tidak sampai kepada sekolah. Disebabkan ini, guru dan pelajar tidak mendapat pendedahan tentang usaha yang dijalankan oleh pihak KPM (Noraini Idris, 2018). Rentetan itu, kesannya ibu bapa dan masyarakat umum mungkin tidak dapat melihat serta memahami dengan jelas akan potensi pendidikan dalam bidang STEM. Maka, tidak hairanlah sasaran nisbah 60:40 dalam aliran Sains dan Sastera pada tahun 2020 masih jauh tersasar (KPM, 2004; Wan, Shaharuddin dan Noraziah, 2014). Di samping itu, guru sebagai pelaksana kurikulum pendidikan STEM di sekolah didapati kurang kesediaan, kompetensi rendah, tidak signifikan serta pengaplikasian elemen STEM yang rendah semasa proses PdP (Teo, 2008; Buabeng Andoh, 2012; Anjuman dan Wan Hussin, 2013; Bourgonjon, De Grove, De Smet, Van Looy, Soetaert dan Valcke, 2013; Msila, 2015; Ahmad Rizal et al., 2015; Shamsiah dan Azman, 2015). Untuk itu, pengkaji berpendapat perlu dibangunkan suatu instrumen bagi menyiasat sejauh manakah pemboleh ubah faktor konteks pelaksanaan elemen pendidikan STEM dalam PdP guru agar dapat memaksimumkan sumber manusia ke arah objektif diharapkan. Melalui usaha pembangunan instrumen ini memungkinkan usaha menjawab permasalahan tersebut.

\section{Tujuan Kajian}

Kajian ini dijalankan bertujuan untuk membina dan mengesahkan Soal Selidik Faktor Konteks (SSFK) Pelaksanaan Elemen Pendidikan STEM dalam Pengajaran dan Pembelajaran Guru.

\section{Reka Bentuk Kajian dan Metodologi}

Kajian ini menggunakan reka bentuk kajian kuantitatif iaitu jenis tinjauan. Penyelidik telah mengedarkan borang soal selidik melibatkan 825 orang guru dari tujuh buah Pejabat Pendidikan Daerah (PPD) di Negeri Sabah, iaitu PPD Kota Kinabalu, PPD Penampang, PPD Kudat, PPD Kunak, PPD Lahad Datu, PPD Semporna dan PPD Sandakan yang dikenal pasti telah melaksanakan penerapan elemen penddikan STEM dalam PdP. Penentuan lokasi kajian dilakukan mengambil kira kesesuaian instrumen yang dibina agar releven ditadbir kepada guruguru di sekolah berkenaan. Dalam kajian ini, pengkaji menggabungkan teknik pensampelan berstrata berkadar dan memilih sampel secara rawak mudah, iaitu bagi memungkinkan kebarangkalian setiap populasi dipilih daripada setiap kumpulan terlibat. Pengkaji mendapat kerjasama baik daripada JPN Sabah, pihak PPD, pihak pentadbiran sekolah serta guru-guru terlibat. Selanjutnya, sebelum borang soal selidik ditadbir, pautan 'google forms' borang soal selidik berserta panduan dan arahan disediakan dan dijelaskan kepada pentadbir dan guru berkenaan. Selanjutnya, hasil kutipan data, pengkaji berjaya memperolehi 825 set, iaitu melebihi jumlah minimum saiz responden berdasarkan jumlah item soal selidik Chua (2014). 


\section{Instrumen Soal Selidik}

Instrumen kajian yang dibangunkan, iaitu Soal Selidik Faktor Konteks (SSFK) terdiri daripada 36 item. Soal selidik ini menggunakan jenis skala Likert lima mata seperti diperincikan dalam Jadual 1.1. Soal selidik faktor konteks melibatkan persepsi guru sebagai pelaksana bertunjangkan latar belakang penataran dan penguasaan maklumat asas guru, iaitu merangkumi sub-konstruk perolehan pengetahuan dan maklumat tentang pendidikan STEM, penguasaan guru terhadap konsep dan tujuan pendidikan STEM, ciri-ciri PdP STEM serta peranan guru dalam melaksanakan pendidkan STEM di sekolah.

\section{Jadual 1.1: Penggunaan Jenis Skala Likert Lima Mata}

\begin{tabular}{|c|c|c|c|}
\hline Mata & Tafsiran & Sub-Konstruk & Sumber \\
\hline $\begin{array}{l}1 \\
2 \\
3 \\
4 \\
5\end{array}$ & $\begin{array}{l}\text { Tidak Pernah - Never } \\
\text { Jarang - Rarely } \\
\text { Kadang-Kadang - Sometimes } \\
\text { Kerap - Often } \\
\text { Selalu - Always }\end{array}$ & $\begin{array}{l}\text { - Perolehan Maklumat } \\
\text { - Konsep dan Tujuan } \\
\text { - Ciri-Ciri } \\
\text { Pelaksanaan }\end{array}$ & Vagias (2006) \\
\hline $\begin{array}{l}1 \\
2 \\
3 \\
4 \\
5\end{array}$ & $\begin{array}{l}\text { Sangat Tidak Puas Hati - } \\
\text { Very Dissatisfied } \\
\text { Agak Tidak Puas Hati - } \\
\text { Somewhat Dissatisfied } \\
\text { Tidak Pasti Puas Hati atau Tidak } \\
\text { Puas Hati - Neither Satisfied nor } \\
\text { Dissatisfied } \\
\text { Agak Puas Hati - Somewhat Satisfied } \\
\text { Sangat Puas Hati - Very Satisfied }\end{array}$ & - Peranan Guru & Vagias (2006) \\
\hline
\end{tabular}

\section{Prosedur Pembangunan Instrumen}

Terdapat pelbagai pandangan berkenaan cara atau prosedur bagi membentuk suatu instrumen dengan baik. Namun, dalam konteks kajian ini pengkaji mengaplikasikan tatacara pembangunan instrumen oleh Walker \& Fraser (2005) yang diperincikan dalam tiga peringkat utama pembentukan instrumen, iaitu;

\section{Peringkat Pertama - Mengenal Pasti Konstruk Utama}

Kajian literatur dilakukan dengan meneroka pelbagai sumber rujukan seperti jurnal dan artikel daripada kajian-kajian terdahulu sama ada dari dalam mahupun luar negara. Langkah ini penting untuk mengenal pasti konsep dan komponen utama yang berkaitan dengan konteks kajian. Selain itu, pengkaji meneroka instrumen-instrumen berkaitan yang pernah dibina sebelum ini. Tujuannya adalah untuk mengetahui konstruk dan item yang telah dibina. Hal ini penting kerana sekiranya terdapat konstruk atau item yang bersesuaian, ia boleh diubahsuai mengikut kesesuaian konteks kajian ini. Seterusnya, proses memperoleh maklumat, pendapat dan idea berkaitan daripada panel pakar berkaitan dilakukan bagi pemilihan dan penentuan konstruk utama berdasarkan tinjauan literatur, instrumen sedia ada dan perbincangan (pakar 
terlibat). Berdasarkan usaha penerokaan literatur, dirumuskan perincian konstruk soal selidik yang digunakan seperti dalam Jadual 1.2.

\section{Jadual 1.2: Penentuan Sub-Konstruk SSFK}

\begin{tabular}{|c|c|c|}
\hline Konstruk & $\begin{array}{c}\text { Sub-Konstruk } \\
\text { Yang Diukur } \\
\end{array}$ & Sumber \\
\hline \multirow[t]{4}{*}{$\begin{array}{l}\text { Faktor Konteks } \\
\text { Pelaksanaan } \\
\text { Elemen } \\
\text { Pendidikan } \\
\text { STEM Dalam } \\
\text { PdP Guru }\end{array}$} & $\begin{array}{c}\text { Perolehan } \\
\text { Maklumat dan } \\
\text { Pengetahuan } \\
\text { Pelaksanaan } \\
\text { Elemen } \\
\text { Pendidikan } \\
\text { STEM Dalam } \\
\text { PdP }\end{array}$ & $\begin{array}{l}\text { Stufflebeam (1983), Stufflebeam \& Shinkfield } \\
\text { (1984, 2007), Stufflebeam et al. (1971), } \\
\text { Ausubel (1983), Jamil (2002), Mazuien } \\
\text { (2013), Crispina (2015) }\end{array}$ \\
\hline & $\begin{array}{l}\text { Konsep dan } \\
\text { Tujuan } \\
\text { Pelaksanaan } \\
\text { Elemen } \\
\text { Pendidikan } \\
\text { STEM Dalam } \\
\text { PdP }\end{array}$ & $\begin{array}{l}\text { Stufflebeam (1983), Stufflebeam et. al. } \\
\text { (1971), Stufflebeam \& Shinkfield (1984, } \\
\text { 2007), Ausubel (1983), Abdul Raof (1990), } \\
\text { Azizi (2001), Panduan Pelaksanaan STEM } \\
\text { dalam PdP (BPK, 2016), Buku Penerangan } \\
\text { KSSM (2016) }\end{array}$ \\
\hline & $\begin{array}{l}\text { Ciri-Ciri } \\
\text { Pelaksanaan } \\
\text { Elemen } \\
\text { Pendidikan } \\
\text { STEM Dalam } \\
\text { PdP }\end{array}$ & $\begin{array}{l}\text { Stufflebeam (1983), Stufflebeam et. al. } \\
\text { (1971), Stufflebeam \& Shinkfield (1984, } \\
\text { 2007), Ausubel (1983), Azizi (2001), Panduan } \\
\text { Pelaksanaan STEM dalam PdP (BPK, 2016), } \\
\text { Buku Penerangan KSSM (2016) }\end{array}$ \\
\hline & $\begin{array}{l}\text { Peranan Guru } \\
\text { Dalam } \\
\text { Melaksanakan } \\
\text { Elemen } \\
\text { Pendidikan } \\
\text { STEM Dalam } \\
\text { PdP } \\
\end{array}$ & $\begin{array}{l}\text { Stufflebeam (1983), Stufflebeam et al. (1971), } \\
\text { Stufflebeam \& Shinkfield (1984, 2007), } \\
\text { Ausubel (1983), Azizi (2001), Panduan } \\
\text { Pelaksanaan STEM dalam PdP (BPK, 2016), } \\
\text { Buku Penerangan KSSM (BPK, 2016) }\end{array}$ \\
\hline
\end{tabular}

\section{Peringkat Kedua - Pembinaan Item Dalam Setiap Konstruk}

Peringkat kedua melibatkan pembinaan item dalam setiap konstruk dengan mengadaptasi item yang bersesuaian daripada instrumen sedia ada untuk dimasukkan sebagai item dalam instrumen baru. Selain itu, item-item baru juga dibina berdasarkan literatur dan perbincangan untuk setiap konstruk yang dikenalpasti. Untuk itu, kesahan pakar yang berpengalaman luas dalam bidang kajian telah dilaksanakan (Jadual 1.3). Kesahan instrumen melalui semakan pakar bermanfaat dilakukan terutamanya dalam mengesahkan kesesuaian item, kesepadanan konstruk dan keserasian skala pegukuran dalam borang soal selidik yang dibina. Jadual 1.4 memperincikan penentuan taburan item soal selidik. 
Jadual 1.3: Senarai Panel Pakar Kajian

\begin{tabular}{|c|c|c|c|c|}
\hline Bil & $\begin{array}{l}\text { Panel } \\
\text { Pakar }\end{array}$ & $\begin{array}{c}\text { Bidang } \\
\text { Kepakaran }\end{array}$ & $\begin{array}{l}\text { Institusi / } \\
\text { Jawatan }\end{array}$ & Pengalaman \\
\hline 1 & $\begin{array}{l}\text { Prof. Dr. A (Pakar } \\
\text { 1) }\end{array}$ & $\begin{array}{l}\text { Pendidikan } \\
\text { STEM }\end{array}$ & $\begin{array}{l}\text { National STEM } \\
\text { Movement }\end{array}$ & 30 Tahun \\
\hline 2 & $\begin{array}{l}\text { Prof. Dr. B (Pakar } \\
\text { 2) }\end{array}$ & $\begin{array}{l}\text { Statistik dan } \\
\text { Kuantitatif }\end{array}$ & $\begin{array}{l}\text { Pusat Pengajian Sains } \\
\text { FPP, UNISZA }\end{array}$ & 32 Tahun \\
\hline 3 & $\begin{array}{l}\text { Prof. Dr. C (Pakar } \\
\text { 3) }\end{array}$ & $\begin{array}{l}\text { Pendidikan } \\
\text { Sains }\end{array}$ & $\begin{array}{c}\text { Pensyarah } \\
\text { Kanan FPP, UMS }\end{array}$ & 30 Tahun \\
\hline 4 & $\begin{array}{l}\text { Prof. Madya Dr. D } \\
\text { (Pakar 4) }\end{array}$ & $\begin{array}{l}\text { Pendidikan } \\
\text { STEM }\end{array}$ & $\begin{array}{c}\text { Pensyarah } \\
\text { Kanan FPP, UMS }\end{array}$ & 30 Tahun \\
\hline 5 & $\begin{array}{l}\text { Prof. Madya Dr. E } \\
\text { (Pakar 5) }\end{array}$ & $\begin{array}{l}\text { Pendidikan } \\
\text { STEM }\end{array}$ & $\begin{array}{l}\text { Pusat Asasi } \\
\text { STEM, UMT }\end{array}$ & 30 Tahun \\
\hline 6 & Dr. F (Pakar 6) & $\begin{array}{l}\text { Pendidikan } \\
\text { Matematik } \\
\text { dan Sains }\end{array}$ & $\begin{array}{c}\text { Pensyarah } \\
\text { Kanan, Jabatan } \\
\text { Sains Matematik, UM }\end{array}$ & 10 Tahun \\
\hline 7 & Dr. G (Pakar 7) & $\begin{array}{l}\text { Pendidikan } \\
\text { Sains dan } \\
\text { Teknikal }\end{array}$ & $\begin{array}{l}\text { Pensyarah Kanan, } \\
\text { Jabatan Sains } \\
\text { Teknikal, UPM }\end{array}$ & 21 Tahun \\
\hline 8 & Dr. H (Pakar 8) & $\begin{array}{l}\text { Pendidikan } \\
\text { STEM }\end{array}$ & $\begin{array}{l}\text { Guru Kanan Bidang } \\
\text { STEM, SMK Likas }\end{array}$ & 10 Tahun \\
\hline 9 & Dr. I (Pakar 9) & $\begin{array}{l}\text { Pendidikan } \\
\text { STEM, } \\
\text { Pembanguan } \\
\text { Soal Selidik }\end{array}$ & $\begin{array}{l}\text { Guru Kanan } \\
\text { Bidang STEM, } \\
\text { SK Pengkalan } \\
\text { Tentera Darat }\end{array}$ & 12 Tahun \\
\hline 10 & Dr. J (Pakar 10) & $\begin{array}{l}\text { Pendidikan } \\
\text { STEM, } \\
\text { Pembangunan } \\
\text { Model STEM }\end{array}$ & $\begin{array}{c}\text { Pensyarah } \\
\text { Kanan, } \\
\text { Fakulti Pendidikan } \\
\text { UiTM }\end{array}$ & 12 Tahun \\
\hline 11 & Dr. K (Pakar 11) & $\begin{array}{c}\text { Statistik, } \\
\text { Pembanguan } \\
\text { Soal Selidik }\end{array}$ & $\begin{array}{c}\text { Pensyarah } \\
\text { Kanan, } \\
\text { EiMAS, UKM }\end{array}$ & 19 Tahun \\
\hline 12 & Dr. L (Pakar 12) & $\begin{array}{c}\text { Statistik, } \\
\text { Pengukuran dan } \\
\text { Penilaian }\end{array}$ & $\begin{array}{c}\text { Pensyarah } \\
\text { Kanan, Fakulti } \\
\text { Pendidikan, UKM }\end{array}$ & 38 Tahun \\
\hline 13 & Dr. M (Pakar 13) & $\begin{array}{c}\text { Statistik, } \\
\text { Pengukuran dan } \\
\text { Penilaian }\end{array}$ & $\begin{array}{c}\text { Pensyarah Kanan } \\
\text { Jabatan Asas } \\
\text { Pendidikan dan } \\
\text { Kemanusiaan } \\
\text { Fakulti Pendidikan, UM }\end{array}$ & 29 Tahun \\
\hline
\end{tabular}

Instrumen yang telah disemak oleh pakar ini kemudianya dianalisis dan dibuat penelitian semula berdasarkan komen serta cadangan penambahbaikan yang telah diberikan. Segala komen dan cadangan yang diperolehi diambil kira dan penambahbaikan dilakukan kepada item-item dalam instrumen yang dibina. Langkah Seterusnya adalah menjalankan kajian rintis. Kajian rintis dijalankan bagi menentukan aspek kesahan dan kebolehpercayaan instrumen. 


\begin{tabular}{|c|c|c|c|c|c|c|}
\hline Konstruk & $\begin{array}{c}\text { Bil. } \\
\text { Item }\end{array}$ & $\begin{array}{c}\text { No. } \\
\text { Item }\end{array}$ & $\begin{array}{c}\text { Adopt } \\
(\sqrt{ })\end{array}$ & $\begin{array}{c}\text { Adapt } \\
(\sqrt{ })\end{array}$ & $\begin{array}{c}\text { New } \\
(\sqrt{ })\end{array}$ & Sumber \\
\hline $\begin{array}{c}\text { Perolehan } \\
\text { Maklumat dan } \\
\text { Pengetahuan } \\
\text { Pelaksanaan } \\
\text { Elemen } \\
\text { Pendidikan } \\
\text { STEM Dalam } \\
\text { PdP }\end{array}$ & 10 & $\begin{array}{l}\text { A6 } \\
\text { A5 } \\
\text { A2 } \\
\text { A7 } \\
\text { A10 } \\
\text { A9 } \\
\text { A8 } \\
\text { A1 } \\
\text { A3 } \\
\text { A1 }\end{array}$ & & $\begin{array}{l}\sqrt{ } \\
\sqrt{ } \\
\sqrt{ } \\
\sqrt{ } \\
\sqrt{ } \\
\sqrt{ } \\
\sqrt{ } \\
\sqrt{ } \\
\sqrt{ } \\
\sqrt{ }\end{array}$ & & 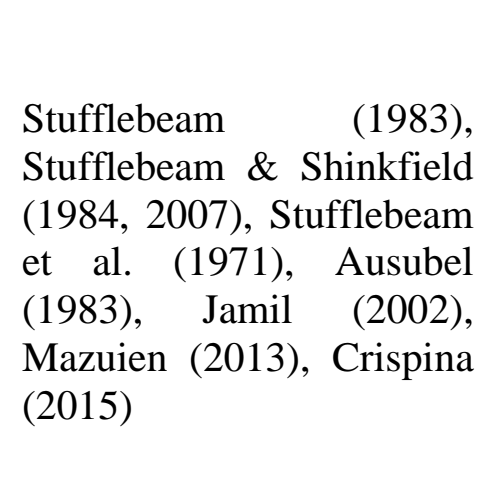 \\
\hline $\begin{array}{l}\text { Konsep dan } \\
\text { Tujuan } \\
\text { Pelaksanaan } \\
\text { Elemen } \\
\text { Pendidikan } \\
\text { STEM Dalam } \\
\text { PdP }\end{array}$ & 13 & $\begin{array}{l}\text { A23 } \\
\text { A22 } \\
\text { A26 } \\
\text { A21 } \\
\text { A17 } \\
\text { A25 } \\
\text { A24 } \\
\text { A31 } \\
\text { A19 } \\
\text { A16 } \\
\text { A13 } \\
\text { A27 } \\
\text { A18 }\end{array}$ & & & $\begin{array}{l}\sqrt{ } \\
\sqrt{ } \\
\sqrt{ } \\
\sqrt{ } \\
\sqrt{ } \\
\sqrt{ } \\
\sqrt{ } \\
\sqrt{ } \\
\sqrt{ } \\
\sqrt{ } \\
\sqrt{ } \\
\sqrt{ } \\
\sqrt{ }\end{array}$ & $\begin{array}{l}\text { Stufflebeam (1983), } \\
\text { Stufflebeam et. al. (1971), } \\
\text { Stufflebeam \& Shinkfield } \\
\text { (1984, 2007), Ausubel } \\
\text { (1983), Abdul Raof (1990), } \\
\text { Azizi (2001), Panduan } \\
\text { Pelaksanaan STEM dalam } \\
\text { PdP (BPK, 2016), Buku } \\
\text { Penerangan KSSM (2016) }\end{array}$ \\
\hline $\begin{array}{c}\text { Ciri-Ciri } \\
\text { Pelaksanaan } \\
\text { Elemen } \\
\text { Pendidikan } \\
\text { STEM } \\
\text { Dalam PdP }\end{array}$ & 5 & $\begin{array}{l}\text { A15 } \\
\text { A14 } \\
\text { A28 } \\
\text { A30 } \\
\text { A20 }\end{array}$ & & & $\begin{array}{l}\sqrt{ } \\
\sqrt{ } \\
\sqrt{ } \\
\sqrt{ } \\
\sqrt{ }\end{array}$ & $\begin{array}{l}\text { Stufflebeam (1983), } \\
\text { Stufflebeam et. al. (1971), } \\
\text { Stufflebeam \& } \text { Shinkfield } \\
(1984, \quad 2007), \quad \text { Ausubel } \\
(1983), \quad \text { Azizi } \quad(2001), \\
\text { Panduan Pelaksanaan } \\
\text { STEM dalam PdP (BPK, } \\
\text { 2016), Buku Penerangan } \\
\text { KSSM (2016) } \\
\end{array}$ \\
\hline $\begin{array}{c}\text { Peranan } \\
\text { Guru Dalam } \\
\text { Melaksanakan } \\
\text { Elemen } \\
\text { Pendidikan } \\
\text { STEM Dalam } \\
\text { PdP }\end{array}$ & 8 & $\begin{array}{l}\text { A35 } \\
\text { A36 } \\
\text { A38 } \\
\text { A34 } \\
\text { A37 } \\
\text { A33 } \\
\text { A39 } \\
\text { A32 }\end{array}$ & & & $\begin{array}{l}\sqrt{ } \\
\sqrt{ } \\
\sqrt{ } \\
\sqrt{ } \\
\sqrt{ } \\
\sqrt{ } \\
\sqrt{ } \\
\sqrt{ }\end{array}$ & $\begin{array}{l}\text { Stufflebeam (1983), } \\
\text { Stufflebeam et al. (1971), } \\
\text { (Stufflebeam \& Shinkfield } \\
(1984, \quad 2007), \quad \text { Ausubel } \\
(1983), \quad \text { Azizi (2001), } \\
\text { Panduan Pelaksanaan } \\
\text { STEM dalam PdP (BPK, } \\
\text { 2016), Buku Penerangan } \\
\text { KSSM (2016) }\end{array}$ \\
\hline
\end{tabular}




\section{Peringkat Ketiga - Menjalankan Kajian Sebenar}

Peringkat ketiga melibatkan pentadbiran instrumen yang telah dibina pada sampel yang lebih besar bagi meningkatkan lagi kesahan dan kebolehpercayaan instrumen. Setelah meneliti tujuan pembinaan item yang dihasilkan ini, penyelidik menetapkan untuk memperoleh kesahan konstruk dengan diperkukuhkan lagi dengan bentuk kesahan yang lain iaitu kesahan muka dan kesahan kandungan. Nunally (1967) menyatakan kesahan konstruk lebih sesuai dan wajar untuk digunakan bagi mengesahkan instrumen yang dibangunkan berbanding prosedur lain. Justeru, dalam konteks kajian ini pengkaji menggunakan keadah Analisis Faktor Penerokaan (EFA) bagi mengesahkan pembinaan konstruk dan item yang telah dibentuk tersebut.

\section{Dapatan Kajian}

\section{Ujian Kenormalan Kajian Rintis.}

Ujian kenormalan taburan data kajian rintis dilakukan ke atas pemboleh ubah Faktor Konteks Pelaksanaan Elemen Pendidikan STEM dalam PdP Guru. Penentuan normaliti data diukur melalui kriteria nilai kepencongan (skewness) dan kecerunan (kurtosis), iaitu berdasarkan indikator julat nilai antara -1 dan 1 yang dikatakan data bertaburan normal (Tabachnick \& Fidell, 2007; Hair et al., 2010). Hasil analisis mendapati, keempat-empat pemboleh ubah kajian menunjukkan nilai skewness dan kurtosis yang normal seperti dipaparkan dalam Jadual 1.5.

Jadual 1.5: Keputusan Ujian Taburan Normaliti Kajian Rintis

\begin{tabular}{ccccccc}
\hline & \multicolumn{2}{c}{$\mathbf{N}$} & \multicolumn{2}{c}{ Skewness } & \multicolumn{2}{c}{ Kurtosis } \\
\cline { 2 - 6 } & & Statistic & Statistic & Std. Error & Statistic & Std. Error \\
\hline $\begin{array}{c}\text { Faktor } \\
\text { Pelaksanaan }\end{array}$ & Konteks & 825 & -.053 & .085 & .294 & .170 \\
& & & & & &
\end{tabular}

\section{Keputusan Analisis Faktor Penerokaan (EFA)}

Analisis faktor dijalankan menggunakan kaedah Extraction of Principal Component dengan Varimax Rotation ke atas setiap item yang mengukur konstruk faktor konteks pelaksanaan elemen pendidikan STEM dalam PdP Guru. Nilai signifikan bagi sukatan kecukupan pensampelan Kaiser-Meyer-Olkin (KMO) dan nilai Ujian Kesferaan Bartlett diteliti sebelum analisis faktor dijalankan. Kaiser (1974) menetapkan nilai KMO $>0.5$ dan nilai ujian kesferaan Bartlett yang cukup besar menunjukkan suatu data memenuhi syarat kebolehfaktoran. Keputusan analisis dalam Jadual 1.6 menunjukkan nilai signifikan bagi ujian KMO dan Ujian Kesferaan Bartlett kajian ini. Keputusan tersebut menunjukkan data ini memenuhi syarat kebolehfaktoran dan analisis faktor dijalankan.

Jadual 1.6: Nilai Kaiser Meyer Olkin dan Signifikan Konstruk

\begin{tabular}{|c|c|c|c|c|c|}
\hline \multirow[b]{2}{*}{ Konstruk } & \multirow{2}{*}{$\begin{array}{c}\text { Kaiser-Meyer- } \\
\text { Olkin Measure } \\
\text { of Sampling } \\
\text { Adequacy } \\
\end{array}$} & \multirow{2}{*}{$\begin{array}{c}\text { Bil } \\
\text { Item }\end{array}$} & \multirow{2}{*}{$\begin{array}{l}\text { Dantonter Ta } \\
\text { Approx. } \\
\text { Chi-Square }\end{array}$} & \multirow[b]{2}{*}{ df } & \multirow{3}{*}{$\begin{array}{c}\text { Sig. } \\
.000\end{array}$} \\
\hline & & & & & \\
\hline Faktor Konteks Pelaksanaan & .963 & 36 & 24901.710 & 666 & \\
\hline
\end{tabular}




\section{Keputusan Bilangan Komponen dan Total Variance Explained}

Jadual 1.7 menunjukkan keputusan dimensi atau komponen dan Total Variance Explained bagi SSFK. Jumlah keseluruhan varians bagi mengukur konstruk faktor konteks adalah $65.765 \%$. Keputusan menunjukkan bilangan komponen dan item bagi setiap komponen adalah bersesuaian mengukur kesemua konstruk kerana jumlah varians keseluruhan melebihi 60\% (Hair et. al., (2010). Berdasarkan keputusan tersebut, terdapat empat faktor utama yang memberi sumbangan besar kepada perubahan varians secara keseluruhan dalam konstruk faktor konteks.

Jadual 1.7: Keputusan Bilangan Komponen dan Total Variance Explained SSFK

\begin{tabular}{ccccccc}
\hline & \multicolumn{3}{c}{$\begin{array}{c}\text { Extraction Sums of Squared } \\
\text { Loadings }\end{array}$} & \multicolumn{3}{c}{$\begin{array}{c}\text { Rotation Sums of Squared } \\
\text { Loadings }\end{array}$} \\
\cline { 2 - 7 } Component & Total & $\begin{array}{c}\text { \% } \\
\text { of Variance }\end{array}$ & $\begin{array}{c}\text { Cumulative } \\
\text { \% }\end{array}$ & Total & $\begin{array}{c}\text { \% } \\
\text { of Variance }\end{array}$ & $\begin{array}{c}\text { Cumulative } \\
\text { \% }\end{array}$ \\
\hline 1 & 16.810 & 45.434 & 45.434 & 7.614 & 20.579 & 20.579 \\
2 & 4.032 & 10.898 & 56.332 & 7.161 & 19.355 & 39.934 \\
3 & 2.187 & 5.910 & 62.242 & 5.464 & 14.767 & 54.702 \\
4 & 1.303 & 3.523 & 65.765 & 4.093 & 11.063 & 65.765 \\
\hline
\end{tabular}

\section{Muatan Faktor Bagi Setiap Item}

Seterusnya, Jadual 1.8 menunjukkan muatan faktor bagi setiap item dalam setiap komponen. Berdasarkan jadual tersebut, bilangan item bagi setiap komponen berjaya diekstrak. Didapati, bilangan item setiap komponen adalah menepati cadangan Pallant (2005), iaitu minmum tiga item diperlukan untuk menerangkan satu komponen atau faktor. Hair et al. (2010) menetapkan bacaan muatan faktor memenuhi tahap minimum yang dianggap baik ialah 0.40 , dan muatan faktor 0.50 atau lebih tinggi, dianggap sangat baik secara praktikal dalam menentukan faktor dalam sesuatu skala pengukuran. Secara keseluruhannya, muatan faktor setiap item dalam julat 0.538 hingga 0.819 .

Jadual 1.8: Muatan Faktor Setiap Item SSFK

\begin{tabular}{cccccc}
\hline & Item & \multicolumn{4}{c}{ Component } \\
\cline { 2 - 5 } & & & & & \\
& & 1 & 2 & 3 & 4 \\
\hline
\end{tabular}

A23 Menunjukkan motivasi melaksanakan elemen pendidikan STEM .776 dalam PdP

A22 Menunjukkan minat melaksanakan elemen pendidikan STEM .762 dalam PdP

A26 Menunjukkan kemampuan mentafsir maklumat dalam .746 melaksanakan elemen pendidikan STEM dalam PdP

A21 Mempamerkan elemen STEM dalam kehidupan sebenar $\quad .719$

A17 Menyepadukan elemen STEM dalam aktiviti kurikulum $\quad .717$

A25 Memanfaatkan teknologi maklumat dalam melaksanakan elemen .708

pendidikan STEM dalam PdP

A24 Menunjukkan penguasaan KBAT dalam melaksanakan elemen .662

pendidikan STEM dalam PdP

A31 Menambahbaik tugasan yang berkaitan elemen pendidikan STEM .660

dalam PdP

Copyright $\odot$ GLOBAL ACADEMIC EXCELLENCE (M) SDN BHD - All rights reserved 
A13 Mengambil kira bidang STEM dalam PdP

A29 Menunjukkan kemahiran proses mereka bentuk suatu projek

A6 Buku Panduan Pelaksanaan Pendidikan STEM

.538

A5 Slot PLC berkaitan pendidikan STEM

A2 Taklimat berkaitan STEM

A7 Surat pekeliling KPM berkaitan pendidikan STEM

\section{Ujian Kebolehpercayaan Kajian Rintis.}

Keputusan ujian kebolehpercayaan diperolehi melibatkan soal selidik bagi mengukur faktor konteks pelaksanaan elemen pendidikan STEM dalam PdP guru. Keputusan analisis kajian rintis terhadap aras kebolehpercayaan alat kajian ditunjukkan dalam Jadual 1.9. Dapatan kebolehpercayaan mendapati instrumen mencapai tahap kebolehpercayaan yang baik dan boleh diterima dalam kajian sebenar, iaitu instrumen faktor konteks $a=0.965$. Bond \& Fox (2007) memerihalkan nilai kebolehpercayaan suatu alat kajian yang berada pada julat 0.9 sehingga 1.0 disifatkan sebagai sangat baik dan efektif dengan tahap konsistensi tinggi untuk digunakan dalam kajian sebenar.

Jadual 1.9: Analisis Keputusan Ujian Kebolehpercayaan Kajian Rintis

\begin{tabular}{ccc}
\hline Instrumen Kajian & Bil. Item & Cronbach's Alpha \\
\hline Soal Selidik Faktor Konteks (SSFK) & 36 & 0.965 \\
\hline
\end{tabular}




\section{Perbincangan}

Kajian ini bertujuan untuk membangunkan soal selidik yang boleh dipercayai dan sah untuk mengukur faktor konteks pelaksanaan elemen pendidikan STEM dalam PdP guru di sekolah menengah. Selepas melalui kesahan muka, kesahan kandungan dan kesahan konstruk melibatkan 13 orang pakar didapati kesemua item adalah sesuai untuk digunakan bagi mengukur konstruk yang dikaji. Seterusnya, analisis faktor telah dijalankan untuk mendapat kesahan konstruk. Nilai muatan faktor bagi setiap item adalah melebihi 0.50 yang ditetapkan (Hair et al., 2010). Perkara ini mengesahkan kesemua item adalah sah digunpakai dalam menjalankan kajian sebenar. Manakala nilai kebolehpercayaan (alpha) instrumen ini adalah $a=0.965$, iaitu berada pada tahap sangat baik dan efektif dengan konsistensi tinggi (Bond \& Fox (2007).

\section{Kesimpulan}

Artikel ini melaporkan pembangunan dan pengesahan Soal Selidik Faktor Konteks Pelaksanaan Elemen Pendiidkan STEM dalam PdP Guru direka khusus untuk mencapai tujuan kajian. Soal selidik ini dibangunkan dengan menggunakan data tanggapan guru-guru sebagai pelaksana elemen pendidikan STEM dalam PdP di sekolah menengah. Secara keseluruhannya, hasil kajian mengesahkan kesahihan dan kebolehpercayaan soal selidik yang dibangunkan dan membuktikan soal selidik ini merupakan suatu alat kajian berguna dalam menilai pelaksanaan elemen pendidikan STEM dalam PdP Guru sejak PPPM 2013-2025 diperkenalkan.

\section{Rujukan}

Abdul Raof Dalip. (1991). Isu-Isu Latihan Mengajar. Fajar Bakti Sdn. Bhd.

Ahmad Rizal Md Rais, Abdul Razaq Ahmad, Anisa Saleha, Norfarizah Adira Abd Hadi. (2015). Kompentensi Guru Terhadap Aplikasi Teknologi Maklumat dan Komunikasi (TMK) dalam Pengajaran dan Pembelajaran. Proceeding 7th International Seminar on Regional Education, November 5-7, Volume 1.

Amimah Mohammad Ayub (2018). Kesedaran Terhad Mengenai Pendidikan STEM Di Malaysia. Prosiding Seminar Kebangsaan Majlis Dekan Pendidikan Universiti Awam, 7-8 November 2018. Penyunting: Rahimah Embong, Hanif Md Lateh @ Junid, Mustafa Che Omar, Mohamad Zaidin Mohamad \& Abdul Hakim Abdullah. eISBN 978-967-2231 03-5.

Buabeng-Andoh, C. (2012). Factors Influencing Teachers' Adoption and Integration of Information and Communication Technology in to Teaching: A Review of the Literature. International Journal of Education and Development using Information and Communication Technology (IJEDICT), 8(1): 136-155.

Anjuman, J. \& Wan Hussin, W. R. (2013). TMK dan Kelestarian Penggunaannya dalam Pengajaran dan Pembelajaran Geografi Di Sekolah. Universiti Sains Malaysia (USM).

Ausubel, D., Novak, J. Y Hanesian, H. (1983). Psicología Educativa Un Punto De Vista Cognoscitivo. México Trillas.

Azizi Yahaya. (2001). Penggunaan Model Kontek. Input, Proses dan Produk (KIPP) dalam Penilaian Program Pembelajaran. Sejauh manakah ia relevan? International Conference on Challenges and Prospects in Teacher education, Concorde Hotel Shah Alam 16 \& 17 July 2001. UTM: Skudai, Johor.

Bahagian Pembangunan Kurikulum. (2016). Buku Penerangan Kurikulum Standard Sekolah Menengah. Kementerian Pendidikan Malaysia. Putrajaya.

Bahagian Pembangunan Kurikulum. (2016). Panduan Pelaksanaan Sains, Teknologi, Kejuruteraan dan Matematik (STEM) dalam Pengajaran dan Pembelajaran. Putrajaya. 
Bahagian Pendidikan Guru (BPG). (2009). Dokumen Panduan Standard Guru Malaysia (SGM). Putrajaya.

Bond T. G. \& Fox C.M. (2015). Applying the Rasch Model: Fundamental Measurement in the Human Sciences. Ed. ke-3. L. Erlbaum.

Bourgonjon, J., De Grove, F., De Smet, C., Van Looy, J., Soetaert, R., \& Valcke, M. (2013). Acceptance of Game-Based Learning by Secondary School Teachers. Computers \& Education, 67, 21-35.

Chua, Y.P. (2014). Kaedah penyelidikan: Kaedah dan statistik penyelidikan (3rd ed.). Shah Alam: McGraw-Hill.

Crispina Gregory K Han (2015). Pengaruh aspek konteks, input dan proses terhadap pencapaian pentaksiran kerja amali Sains. [Tesis PhD, Fakulti Psikologi dan Pendidikan. Universiti Malaysia Sabah].

Fazurawati Che Lah. (2018, 08 Okt). Pendidikan STEM. Harian Metro Online, Diperolehi daripada: https://www.hmetro.com.my/bestari/2018/10/384491/pendidikan-stem

Fullan, M. (2011). The New Meaning of Educational Change (4th ed.). Teacher College Press.

Hair, J. F., Black, W. C., Babin, B. J., \& Anderson, R. E. (2010). Multivariate data analysis (7th ed.). Prentice Hall.

Jamil Ahmad. 2002. Pemupukan Budaya Penyelidikan di Kalangan Guru Sekolah: Satu Penilaian. Tesis Doktor Falsafah. Fakulti Pendidikan, Universiti Kebangsaan Malaysia, Bangi.

Joke Voogt \& Natalie Pareja Roblin. (2012). A Comparative Analysis of International Frameworks For 21st Century Competences: Implications for National Curriculum Policies. Journal of Curriculum Studies, Volume 44, 2012-Issue 3.

Kaiser, H. F. (1974). An index of factorial simplicity. Psychometrika, 39, 31-36.

Kementerian Pendidikan Malaysia. (2018). Laporan Tahunan Pelan Pembangunan Pendidikan Malaysia 2013-2025. Kementerian Pelajaran Malaysia (KPM).

Kementerian Pendidikan Malaysia. (2004). National Education Policy. Kementerian Pelajaran Malaysia (KPM).

Mazuien Misran. (2013). Pemahaman Guru Penolong Kanan dalam pelaksanaan pentaksiran berasaskan sekolah (PBS) dalam Kurikulum Standard Sekolah Rendah (KSSR). Fakulti Pendidikan. Johor Bahru: Universiti Teknologi Malaysia.

Meor Ahmad Nasriin Rizal Ishak. (2017, 14 November). Masyarakat perlu perkasa STEM. Berita Harian Online. Diperolehi daripada: https://www.bharian.com.my/berita/pendidikan/2017/11/350539/masyaraka t-perluperkasa-stem

Mohamed, A., Afshari, M., Ghavifekr, S., Siraj, S., \& Bin Abdul Razak, A. (2017). The Use of Instructional Technology in teaching: a comparative analysis. Malaysian Online Journal of Educational Management, 1(1), 1-9.

Mourshed, M., Chijioke, C., \& Barber, M. (2010). How the world's most improved school systems keep getting better. McKinsey \& Company.

Msila, V. (2015). Teacher Readiness and Information and Communications Technology (ICT) Use in Classrooms: A South African Case Study. Creative Education 6, 1973-1981.

Ndubisi Ijeoma. (2018, 12 February). Female empowerment on STEM tool for significant change-NGO. NNN Online. Diperolehi daripada: https://nnn.com.ng/femaleempowerment-on-stem-tool-for-significant- change-ngo/

Noraini Idris. (2019, 18 Mar). Experts: Fewer STEM students will affect nation's talent pool. The Star Online. Diperolehi daripada https://www.thestar.com.my/news/nation/2019/03/18/experts-fewer-stem- studentswill-affect-nations-talent-pool

Copyright $\odot$ GLOBAL ACADEMIC EXCELLENCE (M) SDN BHD - All rights reserved 
Nunnally, J. C. (1967). Psychometric Theory. McGraw-Hill.

Shamsiah Sidek \& Azman Hasan. (2015). Kebolehan Guru-Guru Mata PelajaranGeografi Menggunakan Teknologi Maklumat Dan Komunikasi (TMK) Dalam Pengajaran Dan Pembelajaran Di Sekolah Menengah Malaysia. Journal of Global Business and Social Entrepreneurship (GBSE), Vol. 1: no. 2 (2015) page 35-43.

Siew, N. M., Amir, N., \& Chong, C. L. (2015). The perceptions of pre-service and inservice teachers regarding a project-based STEM approach to teaching science. Springer Plus, $4(1), 1-20$.

Stufflebeam, D. L., \& Shinkfield, A. J. (1984). Systematic Evaluation. Kluwer.

Stufflebeam, D. L., \& Shinkfield, A. J. (2007). Evaluation Theory, Models, \& Applications. Jossey-Bass.

Stufflebeam, D. L. (1983). The CIPP Model for Program Evaluation. In Madaus, G.F, Scriven, M. \& Stufflebeam. d.) Evaluation Models, pp. 140-144. Kluwer- Nijhoff.

Stufflebeam, D.L., Folely, W.J., Gephart, W.J., Guba, E.G., Hammond R.L., Merriman, H.O., \&Provus, M. M. (1971). Educational Evaluation and Decision-making. F.E. Peacock.

Tabachnick, B. G., \& Fidell, L. S. (1996). Using Multivariate Statistics (3rd ed.). Harper Collins.

Teo, T. (2008). Assesing The Computer Attitudes of Student: An asian perspective. Journal of Computers in Human Behavior, 24, 1634-1642.

Vagias, W.M. (2006). Likert-Type Scale Response Anchors. Clemson International Institute for Tourism \& Research Development, Department of Parks, Recreation and Tourism Management. Clemson University, Clemson.

Walker, S., \& Fraser, B. (2005). Development and validation of an instrument assessing distance education learning environments in higher education: the distance learning environment survey (DELES). Learning Environments Research: An International Journal, 8(3), 289-308.

Wan Afizi Wan Hanafi, Shaharuddin Ahmad, Noraziah Ali. (2014). Faktor budaya dan persekitaran dalam prestasi pendidikan anak Orang Asli Malaysia: Kajian kes di Kelantan. Geografia-Malaysian Journal of Society and Space, 10(5), p.107-122. 